\title{
WILEY
}

\section{Journal of Economics}

Den brasilianska kaffespekulationen

Author(s): D. D.

Source: Ekonomisk Tidskrift, Årg. 11, häft 3 (1909), pp. 104-110

Published by: Wiley on behalf of The Scandinavian Journal of Economics

Stable URL: http://www.jstor.org/stable/3437660

Accessed: 27-06-2016 02:33 UTC

Your use of the JSTOR archive indicates your acceptance of the Terms \& Conditions of Use, available at

http://about.jstor.org/terms

JSTOR is a not-for-profit service that helps scholars, researchers, and students discover, use, and build upon a wide range of content in a trusted digital archive. We use information technology and tools to increase productivity and facilitate new forms of scholarship. For more information about JSTOR, please contact support@jstor.org.

Wiley, The Scandinavian Journal of Economics are collaborating with JSTOR to digitize, preserve and extend access to Ekonomisk Tidskrift 


\section{Den brasilianska kaffespekulationen.}

Brasilien är, som bekant, världens förnämsta kaffeproducent. Några tillförlitliga siffror rörande storleken af kaffeproduktionen och dess fördelning på olika länder finnas naturligtvis icke. Men den statistik, som finnes, anger, att Brasilien för närvarande skulle producera c:a $3 / 4$ af världsproduktionen och att en af de till Brasilien hörande staterna, S. Paulo, skulle producera omkring $2 / 3$ af Brasiliens och sålunda $1 / 2$ af världens kaffeproduktion. I en uppsats »La valorisation du café au Brésil» i Annales des sciences politiques för 1908, sid. 587, meddelas efter en brasiliansk författare följande statistik (där siffrorna betyda millioner säckar à 60 kilogram per säck).

$\begin{array}{cccc}\text { År. } & \begin{array}{c}\text { Världsproduktionen } \\ \text { årligt medeltal. }\end{array} & \begin{array}{c}\text { Brasiliens produktion } \\ \text { årligt medeltal. }\end{array} & \begin{array}{c}\text { Konsumtionen } \\ \text { årligt medeltal. }\end{array} \\ 1870-75 & 6,7 & 3,3 & 7,2 \\ 1880-85 & 10,4 & 5,8 & 9,8 \\ 1890-95 & 10,6 & 6,1 & 10,8 \\ 1895-1900 & 13,2 & 8,7 & 13 \\ 1900-05 & 16,3 & 12,4 & 16,3\end{array}$

I en artikel »La valorisation du café» i L'Économiste Européen för den 2 I augusti 1908 uppges produktionen och konsumtionen under de senaste åren ha utgjort (i millioner säckar à 60 kilogram).

År. Världsproduktionen. Brasiliens produktion. Konsumtionen.

\begin{tabular}{|c|c|c|c|}
\hline $1895-96$ & 10,39 & 6,00 & 10,97 \\
\hline I $896-97$ & I $3,9 \mathrm{I}$ & $9,3^{x}$ & 12,42 \\
\hline I $897-98$ & 16,05 & I I, $2 \mathrm{I}$ & I 4,58 \\
\hline I $898-99$ & 13,72 & 9,32 & I 2,99 \\
\hline $1899-1900$ & 13,80 & 9,42 & 14,25 \\
\hline I900-OI & 15,07 & I I, 28 & 13,96 \\
\hline $1901-02$ & 19,79 & $16,1_{4}$ & 15,32 \\
\hline $1902-03$ & I6,66 & I 2,94 & 16,10 \\
\hline $1903-04$ & 15,99 & I I , IO & I 5,59 \\
\hline $1904-05$ & 14.45 & 10,52 & $15,5 \mathrm{I}$ \\
\hline $1905-06$ & I 4,79 & $10,8_{4}$ & $16,{ }_{3} \mathrm{x}$ \\
\hline I $906-07$ & 23,79 & 20,19 & $\mathrm{I} 7, \mathbf{I I}$ \\
\hline $1907-08$ & 14,86 & II,$\infty$ & I6,94 \\
\hline
\end{tabular}


Af dessa siffror framgår, att Brasiliens andel af världsproduktionen varit i ständig tillväxt. Ja, tillväxten af Brasiliens produktion är lika stor som tillväxten af världsproduktionen i dess helhet.

Denna närings betydelse för Brasiliens ekonomi framgăr äfven af att värdet af kaffeexporten från Brasilien 1907 uppgick till öfver hälften af landets hela export. Och det kapital, som är nedlagdt i kaffeproduktionen i staten S. Paulo, uppskattas till nära 4 milliarder francs.

Det är på grund af dessa förhållanden förklarligt, att, då kaffepriserna började visa en stadig tendens att sjunka, Brasiliens kaffeproducerande stater kände sig manade att försöka motverka denna för landet skadliga tendens. Redan år I893 stiftade S. Paulo en lag, som afsåg att hindra tillväxten af kaffeplantager genom att belägga nya sådana med en skatt af två contos (eller 2,000 milreis) pr hektar, hvilket enligt nu gällande kurs ungefär motsvarar 3,200 francs och sålunda innebar detsamma som förbud af nya kaffeodlingar. Emellertid blef denna lag, som I 893 stiftades blott för fem år men sedermera förnyats, så att den fortfarande är gällande, ej med tillbörlig kraft tillämpad förr än från år I903. Då nyodlingar ej bära frukt förr än efter c:a 5 år, har denna lag sålunda icke kunnat inverka på produktionen förr än tidigast under sist förflutna produktionsår, 1907-08.

I slutet af 1905 inträffade en för kaffeproducenterna ödesdiger händelse. Kaffeblomningen under hösten 1905 gaf vid handen, att skörden för år 1906-07 skulle bli exceptionellt stor, och detta löfte blef ock infriadt, såsom af den nyss meddelade statistiken framgår. Man befarade, att den prissänkning, som denna exceptionella skörd skulle medföra, dă den kom ut i marknaden, skulle nedbringa kaffepriset under produktionskostnaderna och därigenom framkalla en kris. För att förhindra detta inledde staten S. Paulo underhandlingar med de andra stater i Brasilien, som voro intresserade i kaffeproduktionen, nämligen Rio och Minas, och resultatet däraf blef öfverenskommelsen i Taubate, som afslöts den 25 februari 1906 och som gick ut på att nämnda stater under medverkan af unionen (Brasiliens förenta stater) skulle, genom uppköp af vederbörlig del af I906 — 07 års skörd, söka upprätthålla kaffepriset vid en viss minimihöjd. För genomförande af denna plan skulle ett lån å I 5 millioner engelska $£$ upptagas, exporten af kaffe beläggas med en exporttull af 3 francs pr säck (för att skaffa medel till lånets förräntning och amortering) samt nya kaffeodlingar tillsvidare förhindras. ${ }^{1}$

1 Öfverenskommelsen innehöll äfven bl. a. bestämmelser i syfte att befrämja en ökning af kaffekonsumtionen och förbättring af kaffets kvalitet. 
Denna konvention, som skulle träda i kraft den I januari 1907 , blef emellertid aldrig vederbörligen utförd. Den påräknade medverkan från unionens sida vägrades, och i följd häraf drogo sig staterna Rio och Minas tillbaka. Det blef därför staten S. Paulo, som ensam fick åtaga sig uppgiften att söka upprätthålla kaffepriset.

Denna stat, som ju också hade det ojämförligt största intresset af att hindra kaffeprisets sjunkande, hade, redan innan konventionen skulle träda i kraft, börjat uppköpa kaffe. Dessa uppköp fortgingo från augusti 1906 till samma månad 1907 , då nära $8 \%$ millioner säckar uppköpts, hvilket ungefär motsvarade den kvantitet, hvarmed skörden $1906-7$ beräknades öfverstiga en normal skörd. ${ }^{1}$ Såsom medverkande orsak till uppköpens afstannande uppges äfven omöjligheten att anskaffa penningar för ytterligare uppköp af kaffe. Uppköpen af de nyssnämnda $8 \frac{1}{2}$ mill. säckar kaffe lär ha betingat en utgift $i$ allt af omkring 450 mill. francs. Penningarna anskaffades genom lån. Sålunda upplånade staten S. Paulo i Europa och Förenta Staterna i augusti 1906 I mill. $£$, i december 1906 ytterligare 2 mill. $£$ och i november 19072 mill. $£$. I oktober 1907 upptog Brasilien i England ett lån å 3 mill. £, som skulle användas till kaffeprisets upprätthållande. Hvad som utöfver de sålunda anskaffade medlen (nominellt 8 mill. $£$ ) behöfdes, anskaffades genom belåning af de uppköpta kaffemängderna, hvilka magasinerades i Havre, Hamburg, Bremen, London, Antwerpen och NewYork.

De motiv och beräkningar, som förmått staten S. Paulo att inlåta sig på denna äfventyrliga spekulation, synas ha varit följande. Det har redan framhållits, att kaffeproduktionen är af eminent betydelse för landets hela ekonomi. Den är redan på grund häraf ock af största betydelse för statens finanser, men därtill kommer, att i följd af finansväsendets anordning skatten på kaffe inbringar nära $2 / 3$ af hela statsinkomsten. Det är sălunda bokstafligen ett vitalt intresse att förhindra, att denna näring undergräfves. Faran häraf, som redan var förberedd genom den starka tillväxt af kaffeodlingen, som pågått under en längre tid (se första tabellen sid. I03) och fått sitt uttryck i ett fortgående betydande prisfall, blef akut genom den exceptionella skörden året $1906-07$, som med omkring 80 procent öfversteg en normal skörd. Regeringen i S. Paulo befarade, att, om detta extra tillskott bragtes i marknaden, kaffepriserna skulle sjunka till en så

\footnotetext{
${ }^{1}$ Af detta förråd såldes något öfver 300,000 säckar under våren 1908 .
} 
låg nivå, att desamma ej skulle täcka produktionskostnaderna. Och då kaffeproducenterna själfva icke voro i stånd att hålla någon betydligare del af skörden frăn marknaden, måste staten ingripa. Med hänsyn till risken för staten af ett dylikt ingripande gjordes gällande, att erfarenheten visat, att någon rekordskörd ej vore att förvänta förr än året I9I I-I2, och att de två närmaste ăren 1907-08 och 1908-09 skulle komma att lämna skördar under det normala på grund af den inverkan, som den exceptionellt rika skörden 1906-07 komme att utöfva på kaffebuskarnas fruktvedsbildning. Under dessa fem år af blott normal eller undernormal produktion skulle den uppköpta kaffemängden kunna försäljas till normala priser.

Emellertid medförde ej denna spekulation det åsyftade resultatet att förhindra prisfall å kaffe; priserna fortforo att sjunka. Detta förhållande innebar nu visserligen ej något bevis för att spekulationen misslyckats; det framhölls sålunda med rätta, att, om kaffeuppköpen ifråga ej skett, priserna skulle fallit ännu mer. Men å andra sidan var det dock tydligt, att regeringen i S. Paulo hoppats att kunna åtminstone hejda prisfallet. En anledning till att detta ej lyckades var nog, att, såsom från flere håll framhölls, den brasilianska statsspekulationen var ägnad att afskräcka andra från all hausse-spekulation i kaffe. Tillvaron af ett kaffelager på en hand af den jättelika storlek, som regeringen i S. Paulo samlat, måste ju alltid framkalla en osäkerhet på marknaden; ehuru så godt som full säkerhet fanns för att regeringen i S. Paulo aldrig skulle komma att spekulera i baisse, kunde det ju dock hända, att finansiella svårigheter skulle kunna tvinga nämnda regering till att sälja en nämnvärd del af det stora förrådet. Denna möjlighet af en hastig betydande prissänkning afskräckte ej blott från spekulationer på hausse, utan föranledde, att de privata kaffelagren höllos mindre än vanligt.

En annan omständighet, som var ägnad att verka nedtryckande på kaffepriserna, var, att den ofvan omnämnda beräkningen angående kaffeskörden året $1907-8$ visade sig vara oriktig. Regeringen i S. Paulo hade, som sagdt, antagit, att nämnda års och påföljande års brasilianska skörd skulle blifva mindre än en normalskörd. I verkligheten uppgick nämnda års skörd till II,x mill. säckar, hvilket motsvarar medeltalet för de fyra år I902-6, som lågo emellan de båda rekordskördarna $190 \mathrm{I}-2$ och 1906-7.

Det finansiella underlaget för kaffespekulationen var icke heller betryggande. Större delen af det för denna spekulation erforderliga kapitalet hade erhållits genom belåning af det uppköpta kaffet, d. v. s. i form af 
lån på kort tid. Denna upplăning var ock mycket dyr, hvartill kommo kostnaderna för magasinering m. m. Enligt en beräkning, som ej synes vara för hög, skulle den årliga kostnaden för kaffespekulationen uppgå till mellan 40 och 50 mill. francs.

Att staten $\mathrm{S}$. Paulo ej var $\mathrm{i}$ stånd att ensam vidmakthålla den inledda kaffespekulationen, blef därför under år 1908 alltmer tydligt. ${ }^{1}$ Den ursprungliga planen, att hela den brasilianska unionen skulle ikläda sig garanti för de erforderliga lånen, måste därför återupptagas. Efter långa underhandlingar har denna angelägenhet i slutet af 1908 ordnats pă följande grunder.

Ett lån på I 5 mill. $£$ upptogs af $\mathrm{S}$. Paulo under full garanti af Brasilien; däraf subskriberades 5 mill. $£$ i Frankrike och lika mycket i England, 2 mill. $£$ i Förenta staterna och samma belopp i Tyskland, samt I mill. $£$ i Belgien. Med de erhållna medlen skola inlösas dels S. Paulo's lån af 1906 å 3 mill. $£$, dels de förskott, som lämnats mot säkerhet af det uppköpta kaffet. Det nya lảnet skall vara till fullo återbetaldt senast den I januari 1919 genom halfåriga amorteringar, men låntagaren har rätt att dessförinnan, när som helst, efter sex månaders uppsägning återbetala hela lånet.

Såsom säkerhet för lånet lämnas, utom, såsom sagdt, Brasiliens borgen, först och främst rätten till exporttullen å kaffe i S. Paulo, hvilken höjts från 3 till 5 francs pr säck och som skall utgå med detta höjda belopp, intill dess det nya lånet blifvit återbetaldt. Det, som inflyter i dylik exporttull, skall öfverlämnas till Brasiliens regering, hvilken tillhandahăller beloppet åt långifvarnes ombud $\mathrm{i}$ och för ränte- och amorteringsbetalningar. Vidare lämnas som säkerhet 7 mill. säckar kaffe, tillhörande S. Paulo, som befinna sig i Europa och Förenta staterna. ${ }^{2}$

Genom denna tull på export af kaffe från S. Paulo och genom försäljning af kaffe från nyssnämnda lager skola årligen minst 45 mill. francs anskaffas, hvilket belopp skall användas, sedan omkostnaderna för lånet och för förvaltningen af S. Paulo's kaffelager samt för kaffets försäljning bestridts, till lånets förräntning och amortering.

${ }^{1}$ Frankrikes Bank nedsatte i maj I908 belåningsvärdet å kaffe.

2 Detta kaffelager var fördeladt sålunda: i Havre I, 876,644, New York I,747,76I, Hamburg 1,621,023, Antwerpen 1,075,000, London 199,500, Rotterdam I55,I9I, Bremen 109,994, Triest 109,807 och Marseille I 00,000 säckar. Summa 6,994,920 säckar. Denna summa understiger det belopp $8, \mathbf{r}$ million säckar, hvartill S. Paulo's hela kaffeförråd uppgafs uppgå våren I908. Differensen får sin förklaring dels af att en del af kaffet är kvar i S. Paulo, dels af att sannolikt en del $\mathrm{i}$ hemlighet sålts sedan våren. 
Kaffelagren skola som sagdt försäljas, och beslutanderätten härom tillkommer en kommission, af hvars medlemmar blott en utses af regeringen i S. Paulo, de öfriga af vissa banker å långifvarnes vägnar. Försäljningen skall börja I910, då minst 500,000 säckar skola säljas. Under år I9I I skola minst 600,000 säckar afyttras och under de följande åren minst 700,000 hvarje år, så att hela förrådet skall vara slutsåldt senast 1920 .

Så länge det nya lånet icke är till fullo betaldt, förbinder sig staten S. Paulo att icke uppköpa något kaffe för egen räkning, vare sig omedelbart eller genom mellanhänder, och vidare att afhålla sig från hvarje lagstiftning eller beslut, innebärande auktorisation af något nytt projekt att upprätthålla kaffets pris.

Slutligen är att nämna, att staten S. Paulo i samma lag (augusti 1908), hvari den allmänna exporttullen på kaffe höjdes till 5 francs pr säck, vidtog bestämmelser för att begränsa exporten af kaffe till ett visst maximum. I detta syfte stadgades, att för kaffe, som exporterades utöfver ett visst belopp, skulle upptagas en extra exporttull af 20 procent af värdet. För året $1 / 7 \quad 1908-30 / 6 \quad 1909$ skall denna tilläggstull drabba hvad som exporteras utöfver 9 millioner säckar; för de två följande åren höjes sistnämnda siffra till resp. $9^{1 / 2}$ och Io millioner. Huruvida S. Paulo gent emot Brasilien eller långifvarne förbundit sig att upprätthålla denna extra tull, har jag mig ej bekant.

Omedelbart efter detta låns afslutande började kaffepriserna stiga. Detta berodde nog delvis på att genom denna lånetransaktion faran för någon hastig realisering af $\mathrm{S}$. Paulo's kaffeförråd var aflägsnad. Men äfven andra orsaker medverkade, nämligen dels rykten (som dock sedermera visade sig vara ogrundade) att utsikterna för 1909-1o års skörd försämrats, dels ock i främsta rummet en ny spekulation i Förenta Staterna, grundande sig på antagandet, att tullen på kaffe i Förenta Staterna skulle vid den snart börjande revisionen af tulltaxan bli höjd.

Meningarna angående detta sålunda afvecklade försök från en stats sida att reglera priset på en vara ha varit mycket delade. Flertalet omdömen gå i den riktningen, att projektet var till sin idé förfeladt och därför dömdt att misslyckas. Andra åter erkänna idéns berättigande och utförbarhet; felet låg $\mathrm{i}$ sättet för utförandet. Förfäktarne af denna senare ståndpunkt framhålla, att $\mathrm{S}$. Paulo ej åsyftat något annat än det, som är uppgiften för hvarje kartell eller trust. Då Brasilien behärskar $2 / 3$ af hela 
världens produktion af kaffe, äger detta land för närvarande synerligen goda utsikter för en prisreglering. Och då denna reglering inskränkte sitt mål till att blott utjämna priserna å kaffe mellan olika år, finnes ju intet skäl att betrakta försöket såsom orimligt. Ty hållas kaffepriserna relativt låga, är det ej stor sannolikhet för att Brasiliens öfvervikt inom kaffeproduktionen skulle allvarligt hotas genom en snabbare utveckling af andra länders produktion. Att försöket i S. Paulo ej hade åsyftad framgăng, berodde på bristen på erforderliga finansiella resurser. Denna brist tvingade S. Paulo att i förtid afbryta uppköpen af kaffe; enligt en uppgift skulle uppköpens inställande skett genom påtryckning af förmedlaren af det lån å 3 mill. $£$, som i okt. I907 upptogs af brasilianska unionen för att stödja kaffespekulationen, i det att ett villkor för lånets beviljande var, att uppköpen skulle inställas.

Hvad som till väsentlig del, särskildt inom den engelska pressen, föranledt de skarpa angreppen på föreliggande prisregleringsprojekt, har nog varit fruktan för att Brasilien eller S. Paulo skulle begagna sin maktställning inom kaffeproduktionen till att öfver höfvan stegra kaffepriserna - och att detta skulle ske med tillhjälp af europeiskt kapital, var ju ej ägnadt att mildra omdömet om de förmenta planerna. Att ett dylikt projekt ej i längden skulle kunna ha framgång, är ju tydligt, enär det skulle vara ägnadt framkalla en ökning af kaffeplantagerna utom Brasilien.

D. D. 